\title{
Corneal donations in South Africa: A 15-year review
}

\author{
N J York, ${ }^{1}$ MB BCh, FC Ophth (SA), Dip Ophth (SA); C Tinley, ${ }^{2} \mathrm{MB}$ ChB, FRC Ophth (Lond) \\ ${ }^{1}$ Department of Ophthalmology, Groote Schuur Hospital and Faculty of Health Sciences, University of Cape Town, South Africa \\ ${ }^{2}$ Department of Ophthalmology, Red Cross War Memorial Children's Hospital and Faculty of Health Sciences, University of Cape Town, South Africa
}

Corresponding author: N York (yorkn20@gmail.com)

\begin{abstract}
Background. Corneal pathology is one of the leading causes of preventable blindness in South Africa (SA). A corneal transplant can restore or significantly improve vision in most cases. However, in SA there is a gross shortage of corneal tissue available to ophthalmologists. Little has been published describing the magnitude of the problem.

Objectives. To describe trends in the number of corneal donors per year in SA, the number of corneal transplants performed each year, the origin of donors, the allocation of corneas to the public or private sector, and the demographics of donors.

Methods. This was a retrospective review of all corneal donations to SA eye banks over the 15-year period 1 January 2002 - 31 December 2016.

Results. There was a progressive year-on-year decline in corneal donors over the study period, from 565 per year in 2002 to 89 in 2016 . As a direct result, there has been an $85.5 \%$ decrease in the number of corneal transplants performed per year using locally donated corneas, from 1049 in 2002 to 152 in 2016 . Of the donors, $48.8 \%$ originated from mortuaries, $39.0 \%$ from private hospitals and $12.2 \%$ from government hospitals; donors from mortuaries showed the most significant decline over the 15 -year period, decreasing by $94.8 \%$. Of donated corneas, $79.3 \%$ were allocated to the private sector and $21.7 \%$ to the public sector. Males comprised $69.1 \%$ of donors, while $77.2 \%$ were white, $14.0 \%$ coloured, 6.3\% black and 2.5\% Indian/Asian. Donor age demonstrated a bimodal peak at 25 and 55 years.

Conclusions. The number of corneal donations in SA has declined markedly, causing the burden of corneal disease requiring transplantation to rise steadily. Population groups with a low donor rate may have cultural and other objections to corneal donation, which should be a major focus of future research and initiatives aimed at reversing the current trends.
\end{abstract}

S Afr Med J 2017;107(8):697-701. DOI:10.7196/SAMJ.2017.v107i8.12482

Corneal pathology is one of the leading causes of preventable blindness around the globe, accounting for $\sim 4 \%$ of preventable blindness worldwide. ${ }^{[1,2]}$ Corneal disease is the cause of visual loss in $11 \%$ of blind or severely visually impaired children and $4 \%$ of blind adults in South Africa (SA). ${ }^{[3,4]}$ A corneal transplant (penetrating or lamellar keratoplasty) can restore or significantly improve vision in the majority of affected patients. Keratoplasty is a surgical procedure whereby diseased cornea is removed and replaced with donor corneal graft tissue. Modern advances in surgical techniques and surgeon expertise have resulted in continual improvements in visual outcomes with these procedures. ${ }^{[5-7]}$

In SA clinical practice, there is a major shortage of corneal graft tissue available to both the private and public sectors. Ophthalmologists in the private sector have to a large extent compensated for this demand-supply inequity by importing donor corneas from countries such as the USA, where local supply of corneal tissue far exceeds demand. ${ }^{[8]}$ For the vast majority of South Africans, however, the cost of these imported corneas (ZAR20 000 25000 per graft) makes them unaffordable. As a result, patients requiring corneal transplant procedures are placed on long waiting lists, and it can be months to years before a cornea becomes available. This prolongs visual disability in patients with a potentially treatable cause. In some cases, these delays result in sight being permanently and irrevocably lost.

Published data on the numbers of locally donated corneal grafts available to ophthalmologists in SA are scarce. A scientific letter on corneal donations at the Gauteng Cornea and Eye Bank reported that the numbers of corneal graft donations in Gauteng Province had steadily diminished between 1998 and 2008. ${ }^{[9]}$ An editorial by Meyer ${ }^{[10]}$ without expanding on the exact year-to-year figures, described a $41 \%$ decline in national corneal donations in SA over the 4-year period $2003-2006 .{ }^{[10]}$ The reasons given for the progressive decline in donations were threefold: legislative changes in SA mortuaries, rising levels of infectious diseases in donors, and lack of public awareness. The most recent published figure for the SA national corneal transplant waiting list was in 2007, and totalled 1738 adults and 146 children. ${ }^{[10]}$ This figure, albeit a large one, is outdated and probably a gross underestimate of the current situation. The number of people waiting for corneal transplantation will continue to rise unless strategies are implemented to reverse these trends.

\section{Objectives}

To describe trends in the number of corneal donors per year, the number of corneal transplants performed each year, the origin of corneal donors, the allocation of corneas and the demographics of corneal donors in SA.

\section{Methods}

A retrospective review was conducted of all corneal donations made to SA eye banks that were operational at any time during the 15-year study period 1 January 2002 - 31 December 2016. Data collection templates were sent to the directors of the four currently operational SA eye banks, namely the Gauteng Cornea and Eye Bank in Johannesburg, the Eye Bank Foundation of South Africa in Cape Town, the KwaZulu-Natal (KZN) Cornea and Eye Association in Durban and the Centre for Tissue Engineering (CTE) in Pretoria (which began eye banking in 2012, after the closure of the previously operational Pretoria Eye Bank in 2010). Data were extracted from the pre-existing databases on corneal donations kept 
by the various eye bank directors in each of their respective banks. The data collection templates were designed to capture information on the numbers of corneal donors per year, the numbers of corneal transplants performed per year using corneas donated to each of the local eye banks, the origin of corneal donors, the distribution of corneas allocated to the public and private healthcare sectors, and the demographics of corneal donors.

The Pretoria Eye Bank and the Port Elizabeth Goosen Eye Bank both closed operations in 2010. The closure of these two eye banks meant that data available from these institutions were limited to the number of corneal transplants performed per year using corneal donations to these banks. No information on donor origin, allocation of grafts or donor demographics was available from these banks.

\section{Ethics approval}

The study was approved by the Human Research Ethics Committee, Faculty of Health Sciences, University of Cape Town (ref. no. 883/2014) and conformed to the principles of the 2013 Declaration of Helsinki. ${ }^{[1]}$

\section{Results}

There was a total of 3738 corneal donors nationally in SA from 2002 to 2016 (Table 1). Given the fact that in most cases each corneal donor is able to donate two corneas, this translated into 6588 locally donated corneal grafts being supplied for corneal transplant procedures over the 15-year study period (Table 2). The Gauteng Cornea and Eye Bank supplied 2530 corneas (38.4\%), the Cape Town Eye Bank (Eye Bank Foundation of SA) supplied 1805 (27.4\%), the combined efforts of the Pretoria Eyebank from 2002 to 2010 and the CTE from 2012 to 2016 (both operating in Pretoria) supplied 1195 (18.1\%), the KZN Cornea and Eye Association supplied 931 (14.1\%) and the Port Elizabeth Goosen Eye Bank supplied 127 (1.9\%). Of the donated corneas, $10.5 \%$ were either discarded or donated for research purposes. The main reasons for discarding donated corneas were positive donor virology (HIV, hepatitis B and C), low endothelial cell count $\left(<2000\right.$ cells $\left./ \mathrm{mm}^{2}\right)$, damaged or scarred grafts, and a positive culture on a swab taken from the graft.

\section{Trends in numbers of corneal donors per year}

The trendline graph of corneal donors nationally (Fig. 1) shows a progressive decline from 565 donors in 2002 to 89 in 2016, an $84.2 \%$ decline over the 15 -year study period. The most significant decline occurred during the period 2005 - 2007, with a 50.9\% drop in donor numbers occurring during that 2 -year period alone. The trend of progressively decreasing corneal donor numbers was consistent across all the SA eye banks.

\section{Trends in numbers of corneal transplants performed per year, using corneas donated to the SA eye banks}

The trends in numbers of corneal transplants performed nationally per year, using locally donated corneas, mirror those found with numbers of corneal donors. The number of transplants per year decreased progressively (Fig. 2), with an $85.5 \%$ decrease over the 15-year period, from 1049 at the start of the study in 2002 to just 152 at the end of the study in 2016. As with the drop in corneal donors, the most significant decrease in numbers occured over the period 2005 - 2007, with a 45.7\% decrease occuring during this time. Again, this trend of progressively decreasing numbers of corneal transplants performed per year was consistent across all the eye banks.

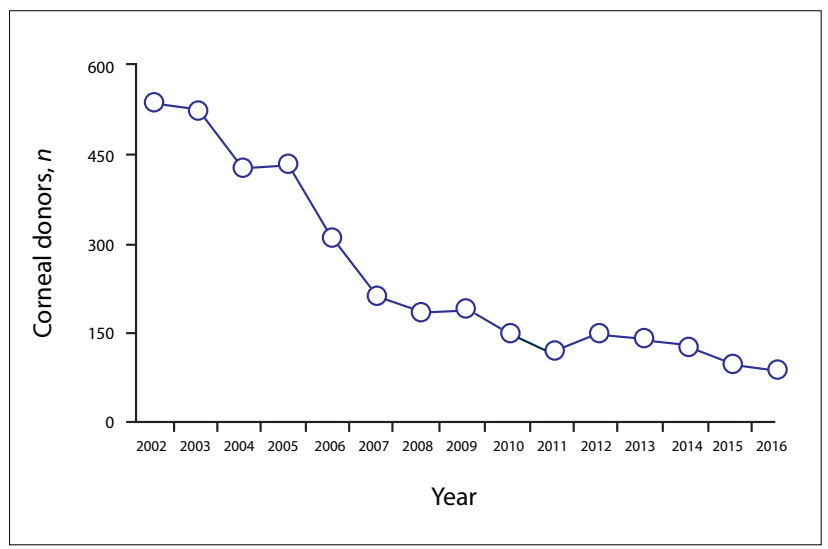

Fig. 1. Trendline graph of numbers of corneal donors per year nationally.

Table 1. Numbers of corneal donors ${ }^{*}$ per year at the South African eye banks

\begin{tabular}{|c|c|c|c|c|c|c|}
\hline Year & Gauteng & Cape Town & KZN & Pretoria & Port Elizabeth & Nationally \\
\hline 2002 & 184 & 164 & 0 & $207^{\dagger}$ & $10^{\dagger}$ & 565 \\
\hline 2003 & 166 & 173 & 42 & $140^{\dagger}$ & $5^{\dagger}$ & 526 \\
\hline 2004 & 137 & 176 & 48 & $58^{\dagger}$ & $9^{\dagger}$ & 428 \\
\hline 2005 & 162 & 172 & 46 & $52^{+}$ & $5^{\dagger}$ & 437 \\
\hline 2006 & 110 & 85 & 67 & $38^{+}$ & $11^{+}$ & 311 \\
\hline 2007 & 88 & 48 & 38 & $33^{+}$ & $8^{\dagger}$ & 215 \\
\hline 2008 & 57 & 46 & 50 & $22^{+}$ & $11^{\dagger}$ & 186 \\
\hline 2009 & 86 & 40 & 32 & $33^{+}$ & $2^{\dagger}$ & 193 \\
\hline 2010 & 70 & 37 & 31 & $2^{+}$ & $9^{\dagger}$ & 149 \\
\hline 2011 & 58 & 37 & 26 & 0 & 0 & 121 \\
\hline 2012 & 68 & 33 & 27 & 23 & 0 & 151 \\
\hline 2013 & 56 & 31 & 29 & 26 & 0 & 142 \\
\hline 2014 & 63 & 17 & 26 & 21 & 0 & 127 \\
\hline 2015 & 51 & 11 & 18 & 18 & 0 & 98 \\
\hline 2016 & 45 & 17 & 19 & 8 & 0 & 89 \\
\hline Total & 1401 & 1087 & 499 & 681 & 70 & 3738 \\
\hline
\end{tabular}


Table 2. Numbers of corneal transplants per year using corneas donated to the South African eye banks

\begin{tabular}{|c|c|c|c|c|c|c|}
\hline Year & Gauteng & Cape Town & KZN & Pretoria & Port Elizabeth & Nationally \\
\hline 2002 & 344 & 315 & 0 & 372 & 18 & 1049 \\
\hline 2003 & 296 & 290 & 72 & 250 & 9 & 917 \\
\hline 2004 & 259 & 286 & 77 & 104 & 17 & 743 \\
\hline 2005 & 289 & 263 & 88 & 93 & 9 & 742 \\
\hline 2006 & 199 & 138 & 129 & 68 & 20 & 554 \\
\hline 2007 & 168 & 85 & 77 & 59 & 14 & 403 \\
\hline 2008 & 103 & 79 & 93 & 39 & 19 & 333 \\
\hline 2009 & 149 & 68 & 56 & 59 & 4 & 336 \\
\hline 2010 & 118 & 61 & 58 & 4 & 17 & 258 \\
\hline 2011 & 106 & 64 & 46 & 0 & 0 & 216 \\
\hline 2012 & 125 & 42 & 53 & 34 & 0 & 254 \\
\hline 2013 & 101 & 37 & 58 & 38 & 0 & 234 \\
\hline 2014 & 104 & 28 & 50 & 36 & 0 & 218 \\
\hline 2015 & 95 & 21 & 36 & 27 & 0 & 179 \\
\hline 2016 & 74 & 28 & 38 & 12 & 0 & 152 \\
\hline Total & 2530 & 1805 & 931 & 1195 & 127 & 6588 \\
\hline
\end{tabular}

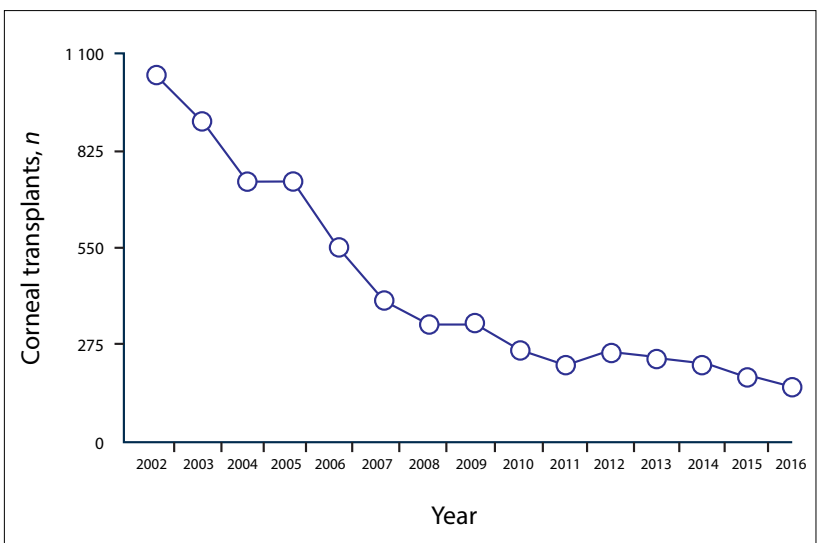

Fig. 2. Trendline graph of numbers of corneal transplants per year nationally using corneas donated to South African eye banks.

\section{Origin of corneal donors}

Data on the origin of corneal donors were obtained from the three SA eye banks that were operational for the entire study period, namely the Gauteng, Cape Town and KZN eye banks. Over the 15-year study period, 1443 donors (48.8\%) originated from mortuaries, 1151 (39.0\%) from private hospitals and 361 (12.2\%) from government hospitals. For 32 donors, the origin was unknown. The number of donors per year arising from private hospitals remained fairly constant over the study period, while the number originating from government hospitals appears to be declining slowly (Fig. 3 ). The number of donors originating from mortuaries showed the most significant reduction over the study period, decreasing by $94.8 \%$ from 211 donors per year in 2002 to 11 per year in 2016. Again, the most marked declines occurred over the period 2005 - 2007, with a $69.8 \%$ drop during this time.

\section{Allocation of donated corneas}

Of the corneas donated to the Gauteng, Cape Town and KZN eye banks, 4041 (79.3\%) were allocated to private sector patients for corneal transplantation, while 1058 (20.7\%) were allocated to the public sector.

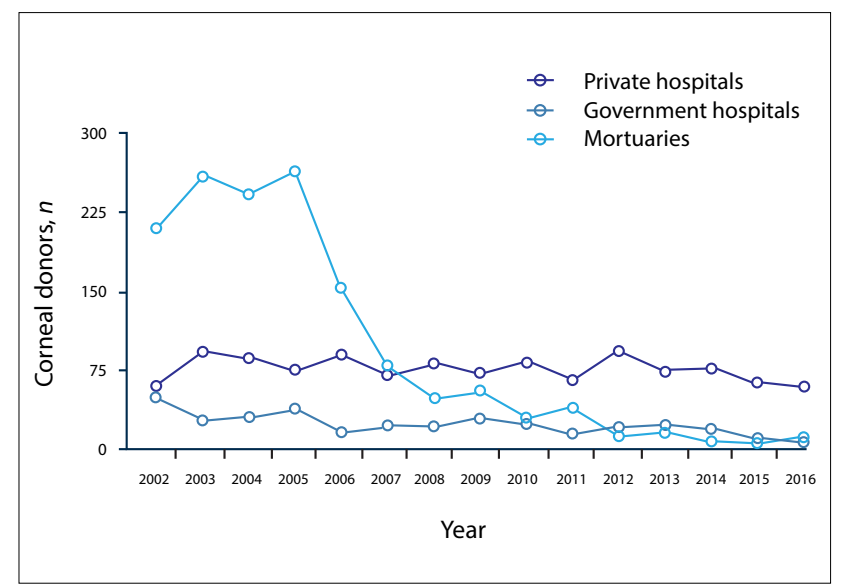

Fig. 3. Trendline graph of origin of corneal donors.

\section{Demographics of corneal donors}

Data on donor demographics were only available from the Gauteng, Cape Town and KZN eyebanks.

\section{Gender of corneal donors}

Of the donors, 2064 (69.1\%) were male and 923 (30.9\%) were female. This approximately 2:1 ratio was consistent across all three eye banks.

\section{Race of corneal donors}

Of the donors, 2280 (77.2\%) were white, 413 (14.0\%) were coloured, $186(6.3 \%)$ were black and $73(2.5 \%)$ were Indian/Asian. White donors made up the largest donor racial group in all three banks, but the proportions of donor races varied substantially (Fig. 4). Race was unknown for 35 donors.

\section{Age of corneal donors}

Of the 2987 donors at the three major eye banks, $342(11.7 \%)$ were aged 0 - 20 years, 957 (32.8\%) 21 - 40 years, $1099(37.7 \%)$ 41 - 60 years and 519 (17.8\%) 61 - 80 years. Age was unknown for 70 donors. There was a bimodal peak in donor age at 25 and 55 years. 


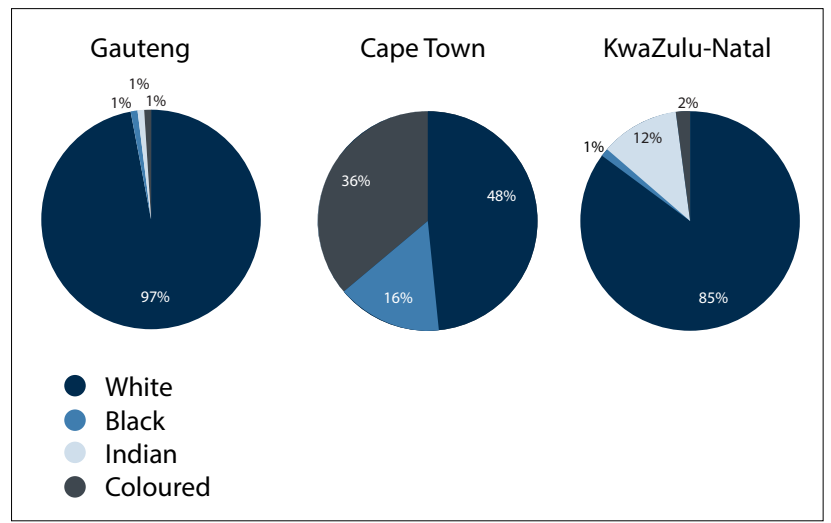

Fig. 4. Race of corneal donors.

\section{Discussion}

This study highlights the alarming trend of progressively decreasing numbers of corneal donors in SA over the 15-year study period. The rapid decline in numbers between 2005 and 2008 coincides with a time of legislative change affecting SA forensic mortuaries. Before 2006, the South African Police Services (SAPS) controlled and managed the forensic mortuaries. Eye bank directors had liberal access to information on deceased persons in the mortuaries and were therefore easily able to identify potential donors and contact their next of kin. This made mortuaries the main source of corneal donors at the time. In 2006, however, changes in legislation shifted the governance of the forensic mortuaries from the SAPS to the National Department of Health $(\mathrm{NDoH})$. The new legislation, with good intentions, placed high emphasis on ethical considerations and confidentiality of deceased individuals at the forensic mortuaries. As a consequence, access to information on potential donors from the mortuaries was dramatically restricted. In addition, new protocols instituted in mortuaries stipulated that telephonic consent from family members was no longer sufficient, and that written consent would be required from a family member who had identified the deceased in person. Given the fact that the time from death to the harvesting of corneas should ideally be within 12 hours, this was very seldom possible. The result was a rapid fall in donors originating from the forensic mortuaries from 2006 onwards. By 2007, this source of corneal donors had fallen to levels below that of donors originating from private hospitals, and these numbers continued to decline throughout the study period.

Corneal donors originating from private and government hospitals were individuals who were either registered organ donors or whose family members had consented to their organ donation after brain death had been declared. Transplant co-ordinators would liase with teams to harvest solid organs and other tissues and then contact the relevant eye bank to harvest the corneas. While the number of corneal donors originating from private hospitals has remained fairly constant throughout the 15-year study period, and private hospitals currently make up the largest source of corneal donors, the actual numbers of donors remain low. The numbers of donors originating from government hospitals have always been low and progressively decreased over the study period. Poor public awareness of organ donation, cultural issues regarding organ donation, high HIV and hepatitis prevalence and poor education and 'buy-in' of medical personnel with regard to referral of potential donors to transplant co-ordinators have all contributed to the low numbers of corneal donors in our government hospitals. In addition, by global standards, SA has a very limited national organ transplant co-ordination programme and little government support and funding of organ donation. Only a very small proportion of patients who die in SA government hospitals therefore become organ donors.

More than two-thirds of donated corneas were allocated to the private sector at all three of the major eye banks, even though there is much greater demand for corneas in the public sector. The reasons for this are two-fold. First, there is no current national system for equitable distribution of corneas between the public and private healthcare sectors. At present, most of the eye banks treat each private practice ophthalmologist and each public sector ophthalmology department as an individual practitioner and attempt to distribute the corneas evenly among them. Because there are many more private ophthalmologists than public ophthalmology departments, this system is heavily skewed in favour of the private sector. The second reason is financial. Eye banks are non-profit organisations, whose sources of income to cover running costs and salaries arise from financial donations and remuneration for corneal tissue supplied. While private sector patients are able to pay for corneal tissue through medical aid funds or personal finances, public sector ophthalmology departments have very limited budgets available to pay for corneal graft tissue and a much slower turnaround time for payments.

There was an approximately 2:1 male preponderance in corneal donors. Of the $48.8 \%$ of donors originating from forensic mortuaries, a large proportion would have died from unnatural causes such as motor vehicle-related accidents, other accidental deaths, murders or suicides. Males are three times more likely than females to die an unnatural death in SA, especially in the younger age group between 15 and 29 years. ${ }^{[12]}$ It is not known whether gender itself influences attitudes towards organ donation in SA, and this may be a topic for future research.

White donors made up the highest proportion in all three major eye banks, despite being one of the smaller race groups in SA. Conversely, black South Africans, the largest race group comprising $79.2 \%$ of our population, ${ }^{[13]}$ accounted for a small fraction of the corneal donor pool. This is probably due to cultural beliefs about organ donation among black South Africans. In a survey on public attitudes towards organ donation in SA, Pike et al. ${ }^{[14]}$ found that while up to $70 \%$ of black respondents said that they would be willing to donate solid organs, only $23 \%$ would be willing to donate their corneas. Cultural beliefs and superstitions may therefore play an even more significant role in the donation of corneas than in the donation of solid organs. The possible cultural barriers to corneal donation among black South Africans require further investigation and should be a key focus point in programmes aimed at improving uptake of corneal donations in SA in the future. The low number of Indian/ Asian donors is probably due to religious beliefs. In the Muslim faith, for example, there is divided opinion on organ donation, with some Islamic scholars saying that it is strictly prohibited, while others argue that the act of saving another's life should make it permissible. ${ }^{[15]}$ The higher proportion of Indian/Asian donors at the KZN eye bank and of coloured donors at the Cape Town eye bank probably reflects the differences in racial demographics in these respective provincial population groups. ${ }^{[13]}$ The bimodal peak in age of donors at 25 and 55 years reflects the fact that the majority of unnatural causes of death occur in the age group $15-29$ years, while the majority of natural causes of death occur in patients aged $>45$ years. $^{[12]}$

This study clearly defines the magnitude of the current corneal donor shortage and the alarming trend of progressively declining corneal donations in SA. Our hope is that this information can be used as a platform on which future strategies aimed at reversing 
these trends can be built. One of the main reasons for the marked decrease in the number of corneal donors has been the legislative changes affecting SA forensic mortuaries. Negotiations should be opened with the $\mathrm{NDoH}$ concerning what measures can be taken to improve the numbers of corneal donors originating from forensic mortuaries, while still maintaining ethical principles and complying with the Protection of Public Information Act. If even a small fraction of the 50000 -plus non-natural deaths per year in $\mathrm{SA}^{[12]}$ could result in corneal donations, the problem would essentially be solved. Other legislative changes that could benefit not only corneal donations but other organ donations as well would be a move from the current 'opt-in' organ donation system to an 'opt-out' system. An 'opt-out' system means that all members of the public are presumed to consent to organ donation, unless they take an active step to opt out. A large-scale review published by a group from Nottingham University in 2014 compared organ donation rates in 48 countries over a 13-year period from 2000 to 2012. They noted that organ donation rates were significantly higher in countries adopting an 'opt-out' system. ${ }^{[16]}$ Wales is the first country in the UK to have shifted to an 'opt-out' system (in 2015), and this resulted in a $24 \%$ increase in transplants in the first year. ${ }^{[17]}$ In June 2016, the British Medical Association, representing 150000 doctors in the UK, voted in favour of a referendum to lobby the British government to change the legislature to an 'opt-out' organ donation system for the entire UK. Spain is currently the world leader in organ donations, with an organ donation rate of $>30$ per million population (pmp) ${ }^{[18]}$ compared with SA's rate of $2-3$ pmp, which is one of the lowest in the world. ${ }^{[19]}$ The reasons for the huge success of the 'Spanish model' of organ donation lie not only in their 'opt-out' legislation, but more importantly in their highly organised and professional national transplant organisation. This state-funded organisation, which is run by the Spanish health department, introduced transplant donor co-ordinators (TDCs) into every hospital in Spain. The TDCs promote organ donation in their hospital, identify potential donors, discuss organ donation with family members, and refer the organ donor to a transplant team after brain death. Similar strategies could be considered by SA policy-makers.

Already there are promising local initiatives attempting to reverse the current trends. The Organ Donor Foundation was established in 1988, with its primary mandate being to raise public awareness of organ donation in SA. Another important collaboration was inaugurated in September 2015, with the formation of the South African Tissue Bank Association. Its purpose is to unite the previously independently operating eye banks and the other tissue banks (harvesting other tissues such as bone, skin and marrow) together under one umbrella body. The objectives are to improve public awareness, standardise procedural protocols, improve education and training of staff and volunteers, improve electronic data collection and publication of donation statistics, and support the individual banks in legal and regulatory matters. Most importantly, it aims to consolidate efforts at lobbying government and other key policy makers to implement new strategies, changes in legislature and the prioritisation of funding, in order to improve numbers of corneal and other tissue donations in the future.

\section{Conclusions}

The number of corneal donations in SA has declined markedly, causing the burden of corneal disease requiring corneal transplantation to rise continually. This study describes the magnitude and trends of the current problem in SA. The demographic data have identified certain low donor rate groups in the SA population, in which there are possible cultural and other objections to corneal donation. These should serve as a major focus of future research and initiatives aimed at reversing the current trends.

Acknowledgements. The eye bank directors Lynne Pickering (Gauteng Cornea and Eye Bank), Sharon Munnik (Eye Bank Foundation of SA), Carol Tonnesen (KZN Cornea and Eye Association), Sandra Venter (Centre for Tissue Engineering) and their staff, in addition to Samantha Nicholls (Organ Donor Foundation), are acknowledged for supplying data on organ donations from databases at their respective organisations.

Author contributions. NJY conceptualised and designed the study, acquired and interpreted the data and drafted the manuscript. CT made substantial contributions to the design of the study and revised the manuscript critically.

Funding. None.

Conflicts of interest. None.

1. Pascolini D, Mariotti SP. Global estimates of visual impairment: 2010. Br J Ophthalmol 2012;96(5):614 618. http://dx.doi.org/10.1136/bjophthalmol-2011-300539

2. National Department of Health. National Guidelines for Prevention of Blindness in South Africa. Cape Town: NDoH, 2002. http://www.westerncape.gov.za/text/2003/blindness.pdf (accessed 21 March 2016).

3. O'Sullivan J, Gilbert C, Foster A. The causes of childhood blindness in South Africa. S Afr Med J 1997;87(12):1691-1695

4. Cockburn N, Steven D, Lecuona K, et al. Prevalence, causes and socio-economic determinants of

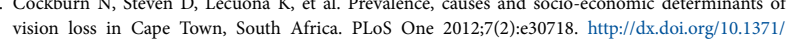
journal.pone. 0030718

5. Wagoner MD, Gonnahel S, Al-Towerki AE; King Khaled Eye Specialist Hospital Cornea Transplant Study Group. Outcome of primary adult penetrating keratoplasty in a Saudi Arabian population. Cornea 2009;28(8):882-890. https://dx.doi.org/10.1097/ICO.0b013e31819b00d8

6. Borderie VM, Sandali O, Bullet J, et al. Long-term results of deep anterior lamellar versus penetrating keratoplasty. Ophthalmology 2012;119(2):249-255. https://dx.doi.org/10.1016/j.ophtha.2011.07.057

7. Price MO, Giebel AW, Fairchild KM, et al. Descemet's membrane endothelial keratoplasty: Prospective multicenter study of visual and refractive outcomes and endothelial survival. Ophthalmology 2009;116(12):2361-2368. https://dx.doi.org/10.1016/j.ophtha.2009.07.010

8. Eye Bank Association of America. 2015 Eye Banking Statistical Report. Washington: EBAA, 2016 http://restoresight.org/wp-content/uploads/2016/03/2015-Statistical-Report.pdf (accessed 23 November 2016).

9. Makgotloe AM, Carmichael TR. Plummeting corneal donations at the Gauteng Cornea and Eye Bank (Scientific Letter). S Afr Med J 2009;99(11):797.

10. Meyer D. The new challenge of corneal transplantation in South Africa (Editorial). S Afr Med J 2007;97(7):512.

11. World Medical Association. World Medical Association Declaration of Helsinki. Ethical Principles for Medical Research Involving Human Subjects. JAMA 2013;310(20):2191-2194. http://dx.doi org/10.1001/jama.2013.281053

12. Statistics South Africa. Mortality and causes of death in South Africa, 2015: Findings from death notification. Pretoria: SSA, 2017. http://www.statssa.gov.za/publications/P03093/P030932015.pd (accessed 1 March 2017).

13. Statistics South Africa. Census 2011. Pretoria: SSA, 2012. http://www.statssa.gov.za/publications P03014/P030142011.pdf (accessed 1 March 2017).

14. Pike RE, Odell JA, Kahn D. Public attitudes to organ donation in South Africa. S Afr Med J 1993;83(2):91-94

15. National Health Services Blood and Transplant. Islam and Organ Donation. Watford: NHSBT, 2012. https://www.organdonation.nhs.uk/about-donation/what-does-my-religion-say/islam/ (accessed 6 March 2016)

16. Shepherd L, O'Carroll RE, Ferguson E. An international comparison of deceased and living organ donation/transplant rates in opt-in and opt-out systems: A panel study. BMC Med 2014;12:131. https:// dx.doi.org/10.1186/s12916-014-0131-4

17. Kendall-Raynor P. Organ donation opt-out law is saving lives in Wales: Number of transplantations has almost trebled this year. Emerg Nurse 2016;24(4):6-6. http://dx.doi.org/10.7748/en.24.4.6.s2

18. Rudge C, Matesanz R, Delmonico FL, Chapman J. International practices of organ donation. Br J Anaesth 2012;108(1):48-55. https://dx.doi.org/10.1093/bja/aer399

19. Miller A. Transplant news (Editorial). Transplant News 2011;10(3):1. http://www.sats.org.za/ news/2011/transplant_vol\%2010\%20no\%2003.pdf (accessed 2 March 2017). 